\title{
Estimation of the infiltration rate of a paddy field in Yun-Lin, Taiwan
}

\author{
Chen-Wuing Liu ${ }^{a}$,*, Shih-Kai Chen ${ }^{b}$, Shew-Wen Jou ${ }^{a}$, \\ Sheng-Feng Kuo ${ }^{\mathrm{b}}$ \\ a Department of Agricultural Engineering, National Taiwan University, Ground Water Research Division, \\ Taipei, Taiwan, 10617, Republic of China \\ ${ }^{\mathrm{b}}$ Chi-Seng Water Management Research and Development Foundation, \\ Taipei, Taiwan, 10617, Republic of China
}

Received 1 February 2000; received in revised form 21 July 2000; accepted 25 October 2000

\begin{abstract}
Flooded paddy fields perform many functions, including not only rice production, but also ecological and environmental conservation, since the paddy field is periodically flooded and thus becomes a major source of ground water recharge. This work estimates the extent of infiltration in a paddy field in Yun-Lin, Taiwan by adopting a one-dimensional Darcy-based soil/water balance model SAWAH (Simulation Algorithm for Water Flow in Aquatic Habitats) and two sets of empirical equations used by the Taiwan Provincial Water Conservancy Bureau. A $7.5-\mathrm{cm}$ thick plow sole layer with a hydraulic conductivity of $0.03-0.055 \mathrm{~cm} /$ day, coupled with the irrigation data obtained from the Ma-Yan station in Yun-Lin is selected to estimate the volumetric amount of annual infiltration in the study region. Simulation results from SAWAH indicate that the plow sole layer controls the movement of infiltrated water, with a rate ranging from 0.2167 to 0.2248 billion cubic meters annually. The infiltration rate estimated from empirical equations ranges from 0.337 to 0.3891 billion cubic meters per year, twice as high as that obtained from SAWAH. This finding suggests that the empirical equations designed to estimate the amount of irrigation water required for rice growth in the
\end{abstract}

\footnotetext{
* Corresponding author. Tel.: + 886-2-362-5432; fax: + 886-22363-9557.
} 
paddy may over-estimate infiltration rates. The simulated annual infiltration rate can be combined with the Geographical Information System to delineate the potential recharge zone for ground water management in Yun-Lin, Taiwan. (C) 2001 Elsevier Science Ltd. All rights reserved.

Keywords: Infiltration; Paddy field; Ground water recharge; Plow sole; Hydraulic conductivity

\section{Introduction}

The downward infiltration of paddy fields is a major source for ground water recharge, since paddy fields are periodically flooded. Many factors influence infiltration from rice fields, including soil texture and structure, top and subsoil thickness, standing water depth, the water and soil temperature and salinity, the depth to the ground water table, and other topographical conditions (Wickham and Singh, 1978). Farmers puddle their paddies to reduce percolation losses during transplanting. Therefore, after long cultivation periods, a 5- to $10-\mathrm{cm}$ plow sole layer (or hard pan), i.e. $20-30 \mathrm{~cm}$ below the ground surface, will form to prevent the infiltration of ponded water from draining further downward. The plow sole layer complicates infiltration by making it a variable saturated flow problem. Recently, several numerical models based on the characteristics of paddy fields in Southeast Asia have been developed (Belmans et al., 1983; McMennamy and O'Tool, 1983; Ten Berge et al., 1992; Bouman et al., 1994; Wopereis et al., 1994). These models can be classified into differential type (or Darcy's type) and integral type models.

The differential type models adopt Darcy's flow equation, the continuity equation, and the unsaturated hydraulic conductivity function to formulate the governing partial differential equation. SWATRE (Belmans et al., 1983), RICEMOD (McMennamy and O'Tool, 1983) and Simulation Algorithm for Water Flow in Aquatic Habitats (SAWAH; Ten Berge et al., 1992) are some examples. Meanwhile, the integral type models utilize physiological rice growth and yield to balance the soil water in the root zone. However, the applications of these models are limited because they do not consider the detailed water movement within the root zone. IRRIMOD (Angus and Zandstra, 1980) and PADDYWATER (Bolton and Zandstra, 1981) are two examples of integral type models.

Empirical equations can calculate and evaluate infiltration rates based on the percentage of clay, loam and sand in a soil sample. Early studies have used the soil water budgeting method to evaluate annual infiltration rates from paddy fields (Chen, 1980). The effective ground water recharge rate is found to be $4400 \mathrm{t} / \mathrm{ha}$ by assuming $25 \%$ of the annual infiltration percolated into deep aquifer. Tzia (1993) suggested that ground water recharge from paddy fields was reduced by 13.5 billion tons between 1980 and 1990 owing to the reduction of the rice paddy area (Tzia and Lin, 1994).

This study attempts to quantitatively evaluate the infiltration rate of paddy fields in Yun-Lin, Taiwan. A one-dimensional Darcy-based soil/water model, SAWAH, and two empirical equations are adopted to to quantify infiltration from 
the Yun-Lin paddy fields. Simulation results obtained using SAWAH agree with the double-ring infiltrometer data. The simulated annual infiltration rate is also calculated to estimate and plan ground water recharge in Yun-Lin, Taiwan.

\section{Estimation methods}

\subsection{SAWAH model}

The one-dimensional soil/water balance model SAWAH developed by Ten Berge et al. (1992) can be used to simulate the water movements within multiple saturated/ unsaturated layers in a ponded condition. The required input data are the soil/water retention function, unsaturated hydraulic conductivity function, and the boundary conditions, including levels of irrigation water, precipitation, evaportranspiration, and the depth of the ground water table. The daily infiltration rate for different irrigation duration periods can be determined according to the given input data. The areal annual infiltration can then be estimated by the following equation:

$$
\text { Areal annual infiltration }\left(m^{3}\right)=\sum P\left(A_{1} f_{1}+A_{2} f_{2}\right) \times 10
$$

where $P$ is the infiltration rate computed with SAWAH for irrigation duration periods of $4,5.5,6$, or 7.5 days; $A_{1}$ and $A_{2}$ denote the irrigation areas for the first and second crop periods, respectively; $f_{1}$ and $f_{2}$ represent irrigation times with specific durations within the first and second crop periods, respectively; and 10 is the unit conversion factor.

\subsection{Empirical equations}

Over the past three decades, two empirical equations have been applied to estimate the irrigation water requirements of rice paddies, the Hydraulic Bureau's equation and Chen/Lee's equation. The Hydraulic Bureau's equation was established by the Japanese during the colonial period in the late nineteenth century, while Chen and Lee's equation was developed over three decades ago. Both equations were based on data from infiltration experiments conducted under a constant water head condition.

\subsection{Hydraulic Bureau's equation}

The Hydraulic Bureau uses the following equation to calculate the steady-state infiltration rate in paddy fields:

$$
P=240 / S I
$$

where $P$ is the infiltration rate ( $\mathrm{mm} /$ day), $S$ denotes the weight percentage of clay particles with a diameter of less than $5 \mu \mathrm{m}$, and $I$ represents an empirical coefficient. 


\subsection{Chen/Lee's equation}

Chen and Lee (1964) thoroughly investigated the steady-state infiltration rates from Taiwanese rice paddy fields, taking 433 Meriiot tube tests from around the island. According to their results, the $\log _{10}$ infiltration rate was linearly related to the water normality, and so can be estimated from the soil texture distribution. Three sets of empirical equations for three types of soil were obtained via statistical regression.

For western alluvial soil $\left\{\begin{array}{l}M_{e}=0.025 S_{a}+0.216 S_{i}+0.603 S_{c} \\ \log _{10} P=1.9394-0.0478 M_{e}\end{array}\right.$

For eastern alluvial soil $\left\{\begin{array}{l}M_{e}=0.019 S_{a}+0.224 S_{i}+0.801 S_{c} \\ \log _{10} P=2.0752-0.0409 M_{e}\end{array}\right.$

For brown soil $\quad\left\{\begin{array}{l}M_{e}=0.021 S_{a}+0.151 S_{i}+0.592 S_{c} \\ \log _{10} P=1.5087-0.0411 M_{e}\end{array}\right.$

where $S_{\mathrm{a}}, S_{\mathrm{i}}$ and $S_{\mathrm{c}}$ are the weight percentage of sand, silt and clay, respectively; $M_{\mathrm{e}}$ denotes the water normality; and $P$ represents the infiltration rate of the paddy field.

The areal annual infiltration estimated by these equations can then be calculated using the following equation:

Areal annual infiltration $\left(m^{3}\right)=P \times\left(A_{1} T_{1}+A_{2} T_{2}\right) \times 10$

where $T_{1}=120$ days and $T_{2}=100$ days are the total irrigation days during the first and second crop periods, respectively; and 10 is the unit conversion factor.

\section{Study area}

\subsection{Area description}

The area irrigated by the Yun-Lin Irrigation Association is located in the south of the alluvial fan of the Chou Shui River (Fig. 1). The region is bordered by the Taiwan Strait in the west, the Central Mountains in the east, the Chou Shui River in the north and the Tsin-Hwa River in the south.

The region extends $80 \mathrm{~km}$ from east to west and $40 \mathrm{~km}$ from north to south, covering all of Yun-Lin county and parts of Nan-Tou and Chai-Yih counties. The average annual precipitation is $1500 \mathrm{~mm}$, concentrated in the 5-month period from May to September. The subtropical weather is hot and humid, with the typhoons that frequently sweep across the island bringing significant precipitation in the summer. Ground water is a vital resource in Yun-Lin and a substantial amount is 


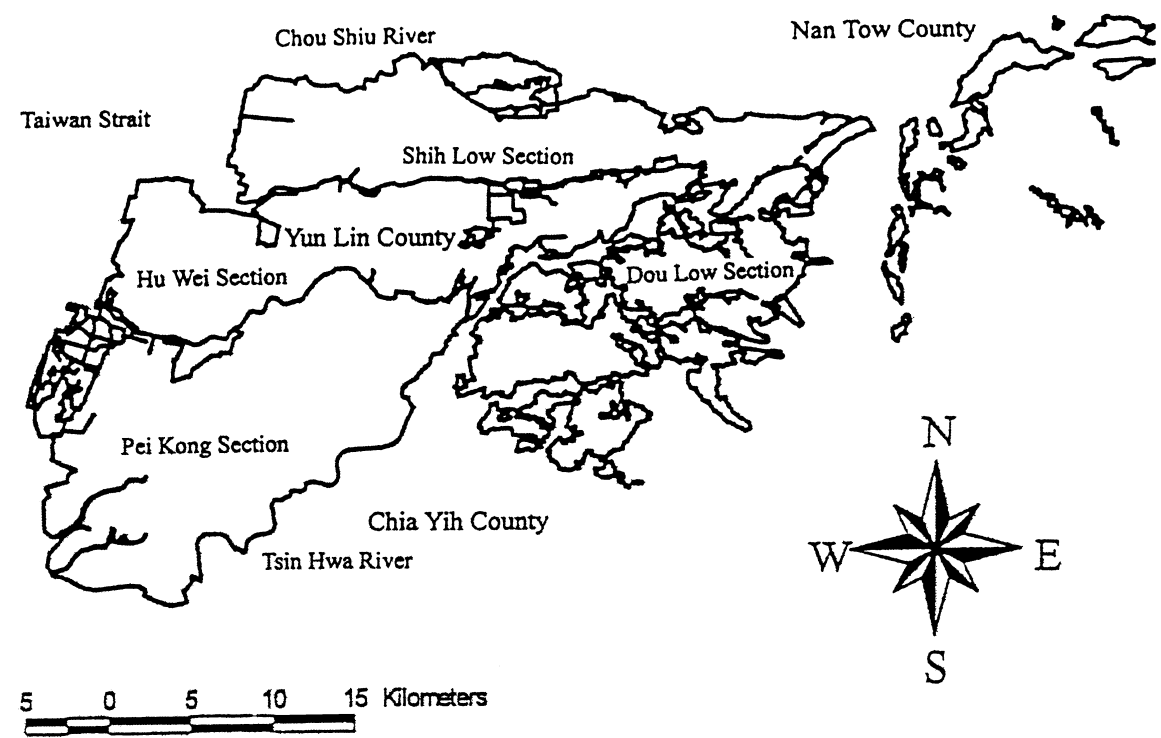

Fig. 1. Location of the Yun-Lin Irrigation Association service region.

continuously extracted, causing land subsidence and seawater intrusion. The YunLin Irrigation Association includes four sections, namely Shih Low, Dou Low, Hu Wei and Pei Kong. The irrigation service area totals 66,381 ha.

\subsection{Paddy environment}

The soil/water distribution of a rice paddy can be illustrated by its cross section, which Fig. 2 displays is divided into four layers (Wopereis et al., 1994):

1. Variable head of irrigated or precipitated ponded water,

2. A low flow resistant muddy layer,

3. A high flow resistant plow sole layer (or hard pan), and

4. A non-puddled subsoil layer

The heterogeneous four-layer soil complicates the infiltration process since the depth of the standing water gradually decreases as the water moves downward. The muddy layer, which contains a mixture of soil particles and irrigation water, becomes saturated. Additionally, the plow sole layer, which has a low hydraulic conductivity, retains the infiltrated water within the muddy layer and remains saturated. Therefore, the highly hydraulically conductive non-puddled subsoil layer receives less water and is unsaturated. Detailed data on the hydraulic characteristics of each layer is necessary to simulate infiltration in the paddy.

The Yun-Lin Irrigation Association employs a rotational irrigation scheme to maximize utilization of limited water resources. The association manages and provides sufficient irrigation water by specific sequential irrigation time steps. The 


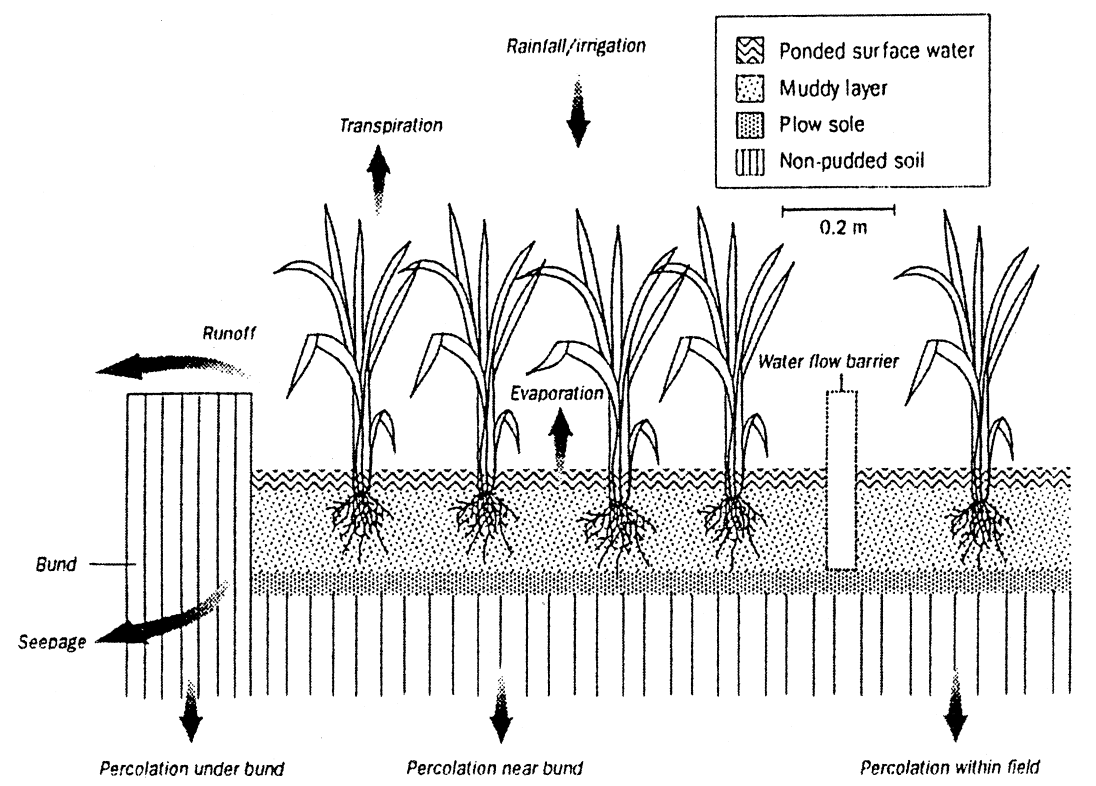

Fig. 2. A schematic diagram of water movement in a paddy environment (after Wopereis et al., 1994).

irrigation water is utilized for rice uptake, evaportranspiration and infiltration, and the ponded irrigation water is no longer supplied as the rice matures.

\subsection{Determining soil/water parameters}

The initial field preparation for a paddy sector of 50 ha requires 3-5 days of flooding, sufficient time to puddle and soften the topsoil. Soil texture and composition after initial field preparation are obtained from the Taiwan Soil Survey Data System developed by National Chun-Hsin University. This system provides 0-30, 30-60, 60-90 and 90-150 cm digital soil texture maps. The relationship between unsaturated hydraulic conductivity $(K)$ and pressure head $(h)$ can be expressed as

$$
\begin{aligned}
& K(h)=K_{s} \mathrm{e}^{\alpha h} \text { at } h \geqslant h_{\max } \\
& K(h)=a[h]^{-1.4} \text { at } h<h_{\max }
\end{aligned}
$$

where $\alpha\left(L^{-1}\right), h_{\max }(L)$ and $a\left(L^{2.4} T^{-1}\right)$ are the empirical soil characteristic parameters, $K_{\mathrm{s}}$ is the saturated hydraulic conductivity.

The soil water content $\theta$ relationship with a pressure head is adopted from Driessen (1986), namely:

$$
h(\theta)=-\exp \left[\left(-\frac{1}{\gamma} \ln \frac{\theta}{\theta_{s}}\right)^{\frac{1}{2}}\right]
$$

where $\gamma$ is a dimensionless parameter related to the soil texture, $\theta$ 's is the saturated water content. 
Table 1

Hydraulic characteristics of different soil types for the Simulation Algorithm for Water Flow in Aquatic Habitats (SAWAH) simulation

\begin{tabular}{lclllll}
\hline Soil type & $\begin{array}{l}\text { Saturated } \\
\text { hydraulic } \\
\text { conductivity } \\
\left(K_{\mathrm{s}}, \mathrm{cm} / \text { day }\right)\end{array}$ & $\begin{array}{l}\text { Soil } \\
\text { characteristic } \\
\text { parameters } \\
\alpha\left(\mathrm{cm}^{-1}\right)\end{array}$ & $\begin{array}{l}\text { Soil } \\
\text { characteristic } \\
\text { parameters } \\
a\left(\mathrm{~cm}^{2.4} / \mathrm{day}\right)\end{array}$ & $\begin{array}{l}\text { Soil } \\
\text { characteristic } \\
\text { parameters } \\
h_{\text {max }}(\mathrm{cm})\end{array}$ & $\begin{array}{l}\text { Soil } \\
\text { characteristic } \\
\text { parameters } \\
\gamma(\text { dimensionless })\end{array}$ & $\begin{array}{l}\begin{array}{l}\text { Saturated } \\
\text { water } \\
\text { content }\end{array} \\
\theta_{\mathrm{s}}(\mathrm{v} / \mathrm{v} \%)\end{array}$ \\
\hline Gravel & 300.0 & 0.1385 & 0.63 & 90.0 & 0.045 & 36.50 \\
Sand & 110.0 & 0.0821 & 3.30 & 125.0 & 0.0366 & 35.00 \\
Fine sand & 50.0 & 0.0500 & 10.90 & 175.0 & 0.0255 & 36.40 \\
Loamy sand & 26.5 & 0.0395 & 16.40 & 200.0 & 0.0299 & 43.90 \\
Sandy loam & 12.0 & 0.0240 & 26.50 & 300.0 & 0.0186 & 50.40 \\
Silty loam & 6.50 & 0.0200 & 47.30 & 300.0 & 0.0165 & 50.90 \\
Loam & 5.00 & 0.0231 & 14.40 & 300.0 & 0.0164 & 50.30 \\
Sandy clay loam & 23.50 & 0.0353 & 33.60 & 200.0 & 0.0101 & 43.20 \\
Silty clay loam & 1.50 & 0.0237 & 3.60 & 300.0 & 0.0108 & 47.50 \\
Silty clay & 1.30 & 0.0480 & 28.20 & 50.0 & 0.0059 & 50.70 \\
Clay & 0.22 & 0.0380 & 4.86 & 80.0 & 0.0043 & 54.00 \\
\hline
\end{tabular}

Table 1 lists the detailed hydraulic parameters of various types of soil used in the SAWAH simulation. The plow sole layer, which exhibits a very high flow resistance, is the key parameter controlling water infiltration. The thickness of the plow sole layer is assumed to be $7.5 \mathrm{~cm}$ and it is assumed to be positioned $20-30 \mathrm{~cm}$ below the ground surface, since the depth of topsoil in paddies that have applied mechanical cultivation methods is approximately $20 \mathrm{~cm}$. The saturated hydraulic conductivity of the plow sole ranges between 0.03 and $0.05 \mathrm{~cm} /$ day (Liu and Chen, 1997). The simulated region is discretized into 10 grids representing the non-puddled subsoil. The pressure head at the top of the plow sole is set as the upper boundary condition, and is the sum of the muddy layer depth and the ponded water depth. The plow sole layer is discretized into two grids, while the non-puddled soil layer is divided into eight grids. Fig. 3 shows the layout of the numerical grids. The initial soil water contents of these grids are assigned to $2 / 3$ of their field capacities $(2 / 3 \mathrm{FC})$ in the first crop period, and are assigned to saturated field capacities (FC) in the second crop period.

The input data for precipitation in the study area are the average monthly rainfall data from 1990 to 1994 obtained from the Yun-Lin Irrigation Association. Meanwhile, the input data for evaporation were obtained from Taiwan Sugar Company stations, while the evaporation data and evaportranspiration rates are estimated by multiplying the rice crop coefficient at a different crop growth stage with the evaporation data.

\section{Model simulation}

\subsection{SAWAH model}

Field experimental data obtained at the Ten-Chung paddy field (Fig. 1) are used to demonstrate the applicability of SAWAH to modeling the infiltration rate of the 


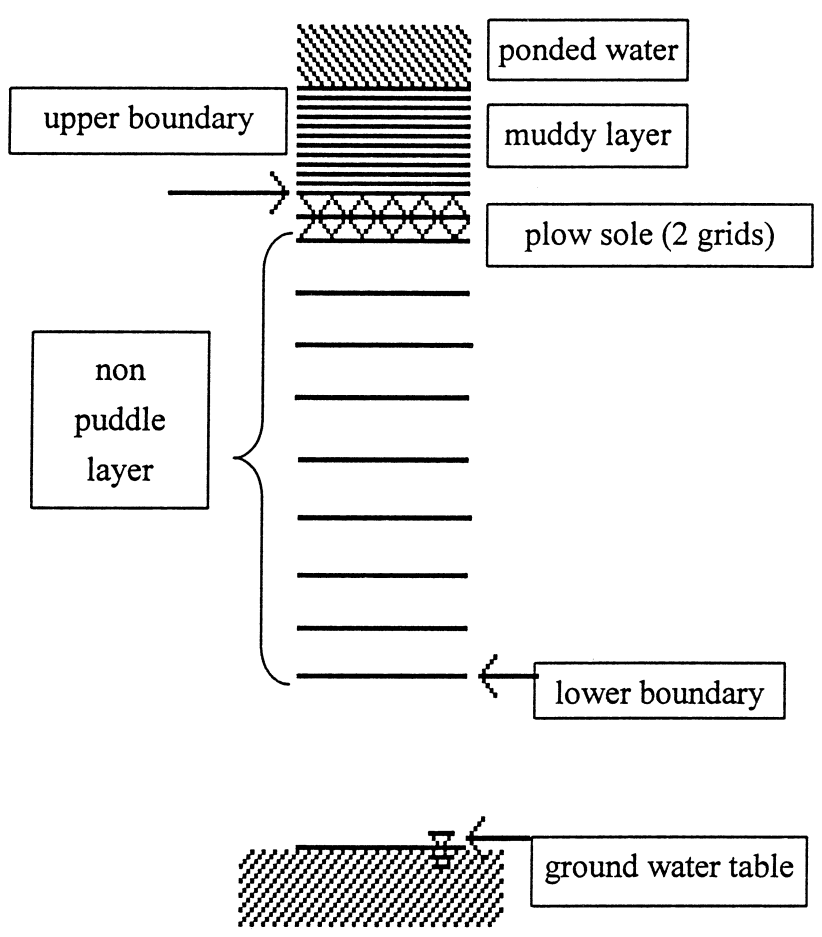

Fig. 3. A schematic numerical grid layout of infiltration in a paddy field.

Yun-Lin paddy field. The muddy layer is $20 \mathrm{~cm}$ deep, and below it is a 7.5-cm thick plow sole layer. The hydraulic conductivity and saturated soil/water content of the plow sole layer are $0.05 \mathrm{~cm} /$ day and $47.18 \%$, respectively, while those of the non-puddled subsoil are $1.1 \mathrm{~cm} /$ day and $48.33 \%$, respectively. Fig. 4 compares the simulated pressure heads with data from field observations. Water movement reaches gravitational flow after the fourth grid, at $10 \mathrm{~cm}$ below the muddy layer.

After experimental data are obtained, the SAWAH model is applied to simulate the infiltration rate of the first crop period at Ma-Yan station in Yun-Lin (Fig. 1). Ma-Yan station maintained an unchanged irrigation scheme, along with complete precipitation and evaportranspiration data from 1992 to 1994. The local soil profiles from top to bottom are the $20 \mathrm{~cm}$ silty loam, followed by a $7.5-\mathrm{cm}$ plow sole layer and then a $120-\mathrm{cm}$ gravel layer. The ground water lies approximately $15 \mathrm{~m}$ below the surface (based on the average value from 1992 to 1994). A rotational irrigation scheme with an irrigation period of 10 days is applied to the paddy. Unlike the second crop period, beginning in the rainy season, the first crop period started from March, when precipitation was less, and thus the subsoil may retain a stable water content profile. To compare the simulated and measured infiltrations, the simulation model adopts the 3 -year average weather data and the same irrigation scheme. The simulated initial subsoil water content is set to $2 / 3 \mathrm{FC}$, which approximately equals the in-situ data from field measurements (Liu and Chen, 1997). 


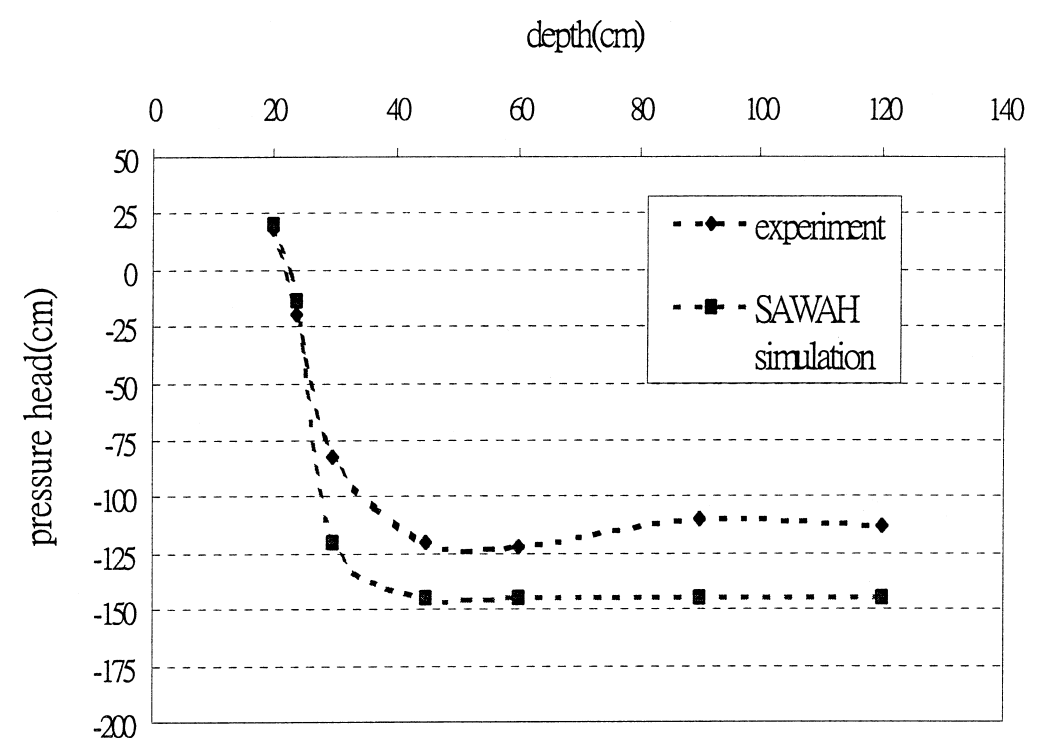

Fig. 4. A comparison of simulated and experimental pressure heads at the Ten-Chung paddy (Yun-Lin, Taiwan).

Bouman et al. (1994), and Liu and Chen (1997) have examined the importance of initial infiltration conditions. Their general conclusions suggest that in well-puddled soils with a less permeable plow sole where hydraulic conductivity is around $10^{-2}$ $\mathrm{cm} /$ day or less, and the thickness of plow sole is $5 \mathrm{~cm}$, the steady-state infiltration rate correlates linearly with the depth of standing water and is less dependent on the hydraulic characteristics and initial water content of the subsoil. However, the variation of infiltration rate versus standing water depth is insignificant in such soils. If the subsoil is dry, the initial infiltration rate may initially be high, but gradually decreases, and reaches the steady-state condition after 1-3 weeks.

Fig. 5 illustrates the simulated infiltrations over 120 days. The same figure also plots the observed infiltrations in 1992, 1993 and 1994, and their trends generally agree. The infiltration reaches $70 \mathrm{~mm}$ after 20 days because of the initial relatively low soil water content. After this point, the infiltration rate slowly drops, ranging from 27 to $40 \mathrm{~mm}$.

The simulated total infiltration during the first crop period is $491.7 \mathrm{~mm}$ (Table 2), below the average of $535.2 \mathrm{~mm}$ obtained from 3-year observation data. The difference can be explained by lateral seepage loss from the permeable bunds.

\subsection{Empirical equations}

Hydraulic Bureau Equations based on the weight percentage of clay particles are used to evaluate the infiltration rate in the paddy. The weight percentages of the clay particles at the Ma-Yan station and the Ten-Chung experimental paddy field are 8 and $5 \%$, and the estimated infiltration rates are 25 and $43.7 \mathrm{~mm} /$ day, respectively. 


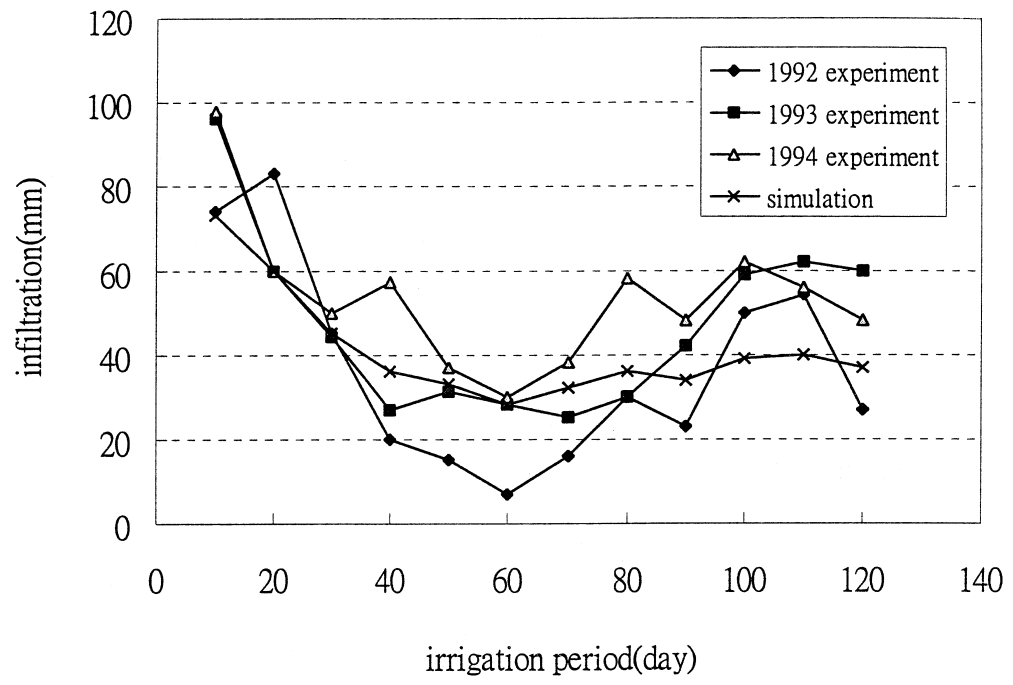

Fig. 5. A comparison of simulated and experimental infiltration at the Ma-Yan paddy (Yun-Lin, Taiwan).

Table 2

Measured and simulated infiltrations $(\mathrm{mm})$ of the first crop period at Ma-Yan Station, Yun-Lin

\begin{tabular}{lcccc}
\hline Ten day period & 1992 measurement & 1993 measurement & 1994 measurement & Simulation \\
\hline 1 & 74.295 & 95.602 & 99.083 & 65.821 \\
2 & 82.865 & 58.663 & 59.886 & 59.424 \\
3 & 45.873 & 43.648 & 50.183 & 44.342 \\
4 & 19.963 & 26.368 & 56.793 & 33.578 \\
5 & 14.333 & 30.146 & 36.663 & 30.221 \\
6 & 6.175 & 29.166 & 29.783 & 28.545 \\
7 & 15.793 & 24.371 & 38.653 & 28.866 \\
8 & 29.743 & 30.333 & 57.403 & 29.324 \\
9 & 22.781 & 42.183 & 47.207 & 31.556 \\
10 & 30.635 & 58.653 & 62.083 & 45.211 \\
11 & 34.095 & 61.393 & 56.456 & 46.269 \\
12 & 26.373 & 60.303 & 47.843 & 48.557 \\
Total & 402.921 & 560.829 & 642.035 & 491.714 \\
\hline
\end{tabular}

Chen and Lee's equation estimated infiltration rates of 30.8 and $8.3 \mathrm{~mm} /$ day by substituting the normality of water contents of 9.42 and $21.4 \%$ at Ma-Yan and Ten-Chung.

Table 3 reveals that the estimates markedly exceed the measured data from the double ring infiltrometric tests. The over-estimation by the empirical equations does not correlate with the field practices at either Ma-Yan or Ten-Chung because only a 6-cm depth of irrigation water is supplied every 6-8 days during each irrigation step. On the other hand, the infiltration rates obtained from field double ring experiments, and presented in Table 3, closely correspond to the results simulated by the 
SAWAH model. This finding suggests that the SAWAH model is more suitable than empirical equations for evaluating, the infiltration of the paddy field.

\section{Estimation of areal infiltration}

\subsection{Areal annual infiltration}

Extensive and complete data are required to assess the areal annual infiltration of the paddy field. The amount of annual infiltration is systematically computed via Eqs. (1)-(4) using the Geographical Information System that overlays the digitized soil texture data of the four-layer soils at the irrigation service region of the Yun-Lin Irrigation Association. Table 4 presents irrigation areas for the first and second crop periods of a 3-year rotational plan obtained from the Yun-Lin Irrigation Association.

The Yun-Lin Irrigation Association manages four work stations, and the total irrigation service area is 66,381 hectares. Obtaining comprehensive in-situ data for SAWAH simulation is difficult. The irrigation water requirements among the four work stations may be correlated since they are all located in the alluvial fan of the Chou Shui River and approximately $90 \%$ of the samples comprise of paddy field topsoil, with a clay weight percentage $\left(S_{\mathrm{c}}\right)$ of below $10 \%$. To assess the infiltration capacity of the subsoil, it is reasonable to assume that the hydraulic conductivity of the plow sole layer can be divided into several scales. Liu and Chen (1997) experimentally showed that the infiltration rate increases from 3.35 to $5.67 \mathrm{~mm} /$ day as the hydraulic conductivity of the plow sole varies from 0.03 to $0.05 \mathrm{~cm} /$ day, which

Table 3

Infiltration rates from empirical estimation and a double ring infiltromenter test

\begin{tabular}{|c|c|c|c|c|c|}
\hline \multirow[t]{3}{*}{ Location } & \multicolumn{5}{|l|}{ Method } \\
\hline & \multicolumn{2}{|c|}{ Hydraulic Bureau formula } & \multicolumn{2}{|c|}{ Chen/Lee formula } & \multirow{2}{*}{$\begin{array}{l}\begin{array}{l}\text { Double ring } \\
\text { infiltrometer test }\end{array} \\
\begin{array}{l}\text { Infiltration rates } \\
\text { ranges }(\mathrm{mm} / \text { day) }\end{array}\end{array}$} \\
\hline & Clay $\%$ & $\begin{array}{l}\text { Infiltration } \\
\text { rate (mm/day) }\end{array}$ & $\begin{array}{l}\text { Water } \\
\text { normality \% }\end{array}$ & $\begin{array}{l}\text { Infiltration } \\
\text { rate (mm/day) }\end{array}$ & \\
\hline Ma-Yan & 8.0 & 25.0 & 9.4 & 30.8 & $0.53-5.15$ \\
\hline Ten-Chung & 5.0 & 43.7 & 21.4 & 8.3 & $1.9-5.15$ \\
\hline
\end{tabular}

Table 4

Annual irrigation areas serviced by the Yun-Lin Irrigation Association

\begin{tabular}{lcc}
\hline & $\begin{array}{l}\text { First crop period } \\
\text { irrigation area (hectares) }\end{array}$ & $\begin{array}{l}\text { Second crop period } \\
\text { irrigation area (hectares) }\end{array}$ \\
\hline First year & 19,314 & 37,519 \\
Second year & 19,603 & 39,390 \\
Third year & 18,915 & 37,116 \\
\hline
\end{tabular}


corresponds to the current irrigation scheme by supplying a depth of 6-10 $\mathrm{cm}$ water over a 6-10-day period. By combining the above finding with the data on the weight percentage of clay particles in the soil provided by the Yun-Lin Irrigation Association, the hydraulic conductivity of the plow sole layer is divided into four scales:

$$
\begin{aligned}
& \mathrm{K}=0.055 \mathrm{~cm} / \text { day }\left(S_{c}<5 \%\right) \\
& \mathrm{K}=0.05 \mathrm{~cm} / \text { day }\left(5 \% \leqslant S_{c}<10 \%\right) \\
& \mathrm{K}=0.04 \mathrm{~cm} / \text { day }\left(10 \leqslant S_{c}<20 \%\right) \\
& \mathrm{K}=0.03 \mathrm{~cm} / \text { day }\left(20 \% \leqslant S_{c}\right)
\end{aligned}
$$

The four different scale hydraulic conductivities above are combined with the digital soil texture map of $0-30,30-60,60-90$ and $90-150 \mathrm{~cm}$, and are adopted for SAWAH simulation. The simulated infiltration rates range from $3.6-5.1 \mathrm{~mm} /$ day. The areal weighted infiltration rate is $4.37 \mathrm{~mm} /$ day, and annual infiltration ranges from 217 to 225 million cubic meters. The normalized annual infiltration (defined as the average annual infiltration amount over the 3 -year cycle) of the first crop period is $4300 \mathrm{~m}^{3} / \mathrm{ha}$, while that of the second crop period is $3700 \mathrm{~m}^{3} / \mathrm{ha}$.

The estimated infiltration rates range from $1.99 \mathrm{~mm} /$ day $(59 \%$ weight of clay particles) to $94 \mathrm{~mm} /$ day $(2.5 \%$ weight of clay particles $)$ using the empirical equation from the Hydraulic Bureau coupled with the digital soil data on clay particles. The amount of annual infiltration ranges from 377 to 390 million cubic meters.

\section{Discussion}

The SAWAH model estimates that the water flux from the plow sole layer ranges from 3.6 to $5.1 \mathrm{~mm} /$ day while the amount of annual infiltration ranges from 217 to 225 million cubic meters. This result closely approximates the estimates from Sino Tech (1995) and Chaing and Ouyang (1996), for annual infiltration of 185 and 201 million cubic meters, respectively. The estimated annual infiltration using the Hydraulic Bureau empirical equation ranges from 377 to 390 million cubic meters, 1.9 times larger than with the SAWAH model. This difference is hypothesized to arise owing to the change of the paddy environment from newly constructed to aged. Therefore, Chen and Lee's empirical equation, developed 35 years ago, and the Hydraulic Bureau's equation, developed by the Japanese in the late nineteenth century, are not suitable, and must be updated to fit current paddy conditions.

Several studies have determined that the quantity of overall annual infiltration in Yu-Lin county ranges from 455 to 489 million cubic meters (Jang, 1996; Liu, 1996; and Chang and Ouyang, 1996). Meanwhile, the amount of annual infiltration from paddy fields estimated using the SAWAH model ranges from 217 to 225 million cubic meters, thus contributing $45 \%$ of the overall annual infiltration in Yun-Lin 
county. This finding suggests that infiltration from paddy fields is important in ground water recharge and water resource conservation.

\section{Conclusion}

Flooded paddy fields serve many functions, such as rice production, and ecological and environmental conservation. A one-dimensional, Darcy-based soil/water balance model SAWAH and two empirical equations used by the Taiwan Provincial Water Conservancy Bureau were adopted herein to evaluate the extent of infiltration from the paddy fields in Yun-Lin. A 7.5-cm thick plow sole layer with a hydraulic conductivity of $0.03-0.055 \mathrm{~cm} /$ day was coupled with the irrigation data obtained from the Ma-Yan station to evaluate the volumetric amount of annual infiltration in Yun-Lin. Simulation results from SAWAH indicated that the plow sole layer controls the movement of infiltrated water with a rate ranging from 0.2167 to 0.2248 billion cubic meters annually. The infiltration rate estimated from empirical equations ranges between 0.337 and 0.3891 billion cubic meters per year, twice that obtained from SAWAH. The empirical equations designed to estimate the quantity of irrigation water required for rice growth in the paddy may over-estimate infiltration rates. The simulated annual infiltration rate is combined with the Geographical Information System to delineate the potential recharge zone for ground water management in Yun-Lin. A three-dimensional model simulation with detailed hydraulic conductivity data of the plow sole layer is suggested here as a future means of accurately evaluating infiltration rates.

\section{Acknowledgements}

The authors would like to thank the National Science Council and the Council of Agriculture of the Republic of China for financial supporting this work under Contract Nos. NSC-87-2621-P-002-035 and No. 87-Nouchan-8.5-Lin-02, respectively.

\section{References}

Angus, J.F., Zandstra, H.G., 1980. Climatic factors and the modeling of rice growth and yield. Proceedings of the WMO-IRRI Symposium on Agrometeorology of the Rice Crop. Los Banos, Philippines, pp. 189-190.

Belmans, C., Wesseling, J.G., Feddes, R.A., 1983. Simulation model of the water balance of a cropped soil: SWATRE. Journal of Hydrology 63, 271-286.

Bolton, F.R., Zandstra, H.G., 1981. A soil moisture based yield model of wetland rainfed rice. IRRI Research Paper 62. IRRI, Los Banos, Philippines.

Bouman, B.A.M., Wopereis, M.C.S., Kroff, M.J., Ten Berge, H.F.M., Tuong, T.P., 1994. Water use efficiency of flooded rice fields. (II) Percolation and seepage losses. Agricultural Water Management 26, 291-304. 
Chaing, L., Ouyang, S., 1996. Preliminary evaluation of groundwater and water balances in Yun-Lin, Taiwan. Proceedings of Chou Shui River Alluvial Fan Groundwater and Hydrogeology Conference. pp. 181-206.

Chen, S., Lee, D.T., 1964. Estimation of irrigation water demand for paddy rice fields by soil moisture equivalent index. Journal of Chinese Agricultural Engineering 10 (4), 15-40.

Chen, S., 1980. The contribution and effects of paddy rice fields to soil and water resource conservation. Evaluation and justification of water distribution for agriculture. Agricultural Engineering Research Center, Taiwan, 1101-1178.

Driessen, P.M., 1986. The water balance of the soil. In: van Keulen, H., Wolf, J. (Eds.), Modeling of Agricultural Production: Weather, Soil and Crops. Simulation Monographs. Pudoc, Wageningen, pp. 76-116.

Jang, C.S., 1996. Three dimensional numerical simulation of the groundwater flow in Yun-Lin, Taiwan, MS thesis. Department of Agricultural Engineering, National Taiwan University, Taipei, Taiwan, pp. $6-17$.

Liu, C.W., Chen, S.K., 1997. Natural recharge of groundwater in the areas from Tai-Shi to Mai-Lau, Taiwan (II). Department of Agricultural Engineering, National Taiwan University, Taipei, Taiwan.

Liu, T., 1996. Groundwater resources in Chou Shui river alluvial fan, Taiwan — studies with the application of ${ }^{14} \mathrm{C}$ and tritium dating/tracer tests. Proceedings of Chou Shui River Alluvial Fan Groundwater and Hydrogeology Conference. pp. 145-164.

McMennamy, J.A., O’Toole, J.C., 1983. RICEMOD: a physiologically based rice growth and yield model. IRRI Research Paper 87, IRRI, Los Banos, Philippines.

Sino Tech 1997. Evaluation the potential development of groundwater in Chou Shui river alluvial fan. Taiwan Hydraulic Bureau.

Ten Berge, H.F.M., Jansen, D.M., Rappoldt, K., Stol. W., 1992. The soil water balance module SAWAH: user's guide and outline. CABO-TPE Simulation Reports, Vol. 22. CABO, Wageningen, the Netherlands.

Tzia, M.H., 1993. The contribution of rice paddy field irrigation to society in Taiwan. Council of Agriculture, Taiwan.

Tzia, M.H., Lin, Y.D., 1994. The strategic plans for encountering the impacts on agriculture from joining GATT in Taiwan - the contribution of the ecology of rice paddy fields to environmental protection and conservation. Water Resource Management Conference, Taipei, pp. 123-137.

Wickham, T.H., Singh, V.P., 1978. Water movement through wet soil. In: Soil and Rice. International Rice Research Institute, Los Banos, Philippines, pp. 337-357.

Wopereis, M.C.S., Bouman, B.A.M., Kroff, M.J., Ten Berge, H.F.M., Maliguya, A.R., 1994. Water use efficiency of flooded rice fields. (I) Validation of the soil-water balance model SAWAH. Agricultural Water Management 26, 277-289. 